\title{
Historiadores
}

\section{no jardim da ciência}

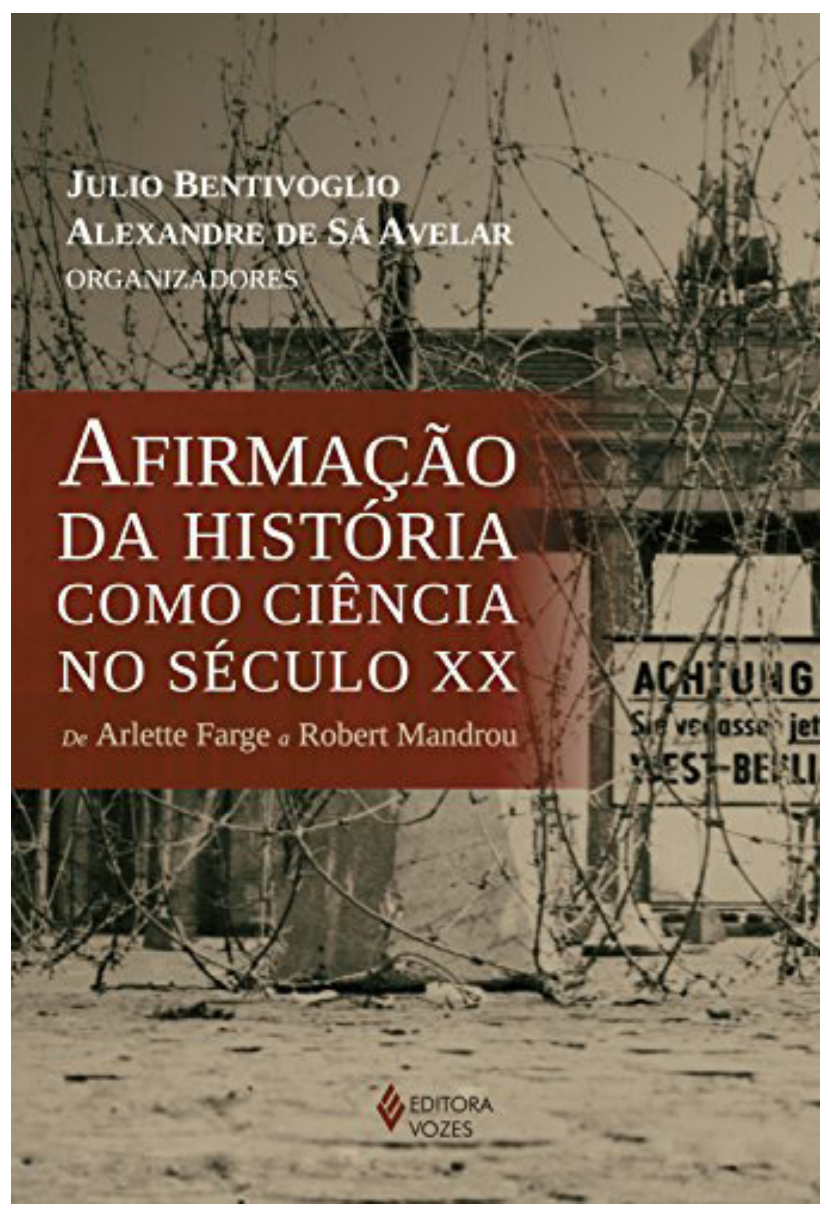

\section{Fábio Franzini}

Doutor em História pela Universidade de São Paulo (USP). Professor do Departamento de História e do Programa de Pós-graduação em História (Mestrado acadêmico e profissional) da Universidade Federal de São Paulo (Unifesp). Autor, entre outros livros, de À sombra das palmeiras: a Coleção Documentos Brasileiros e as transformações da historiografia nacional (1936-1959). Rio de Janeiro: Casa de Rui Barbosa, 2010. fabio.ff.franzini@gmail.com 


\section{Historiadores no jardim da ciência}

Historians in the garden of science

Fábio Franzini

BENTIVOGLIO, Julio e AVELAR, Alexandre de Sá (Orgs.). Afirmação da História como ciência no século XX: de Arlette Farge a Robert Mandrou. Petrópolis: Vozes, 2016, 168 p.

${ }^{1}$ STONE, Lawrence. O retorno da narrativa: reflexões sobre uma nova velha história. In: NOVAIS, Fernando A. e SILVA, Rogerio Forastieri da (Orgs.). Nova história em perspectiva. São Paulo: Cosac Naify, 2013, p. 9 (Vol. 2: Debates).

Historiador: adj., s.m. 1. que ou aquele que se especializou em ou que escreve sobre história ("ciência"); historiógrafo. 2. que ou aquele que narra qualquer acontecimento. 3. que ou quem conta estórias.
\end{abstract}

Dicionário Houaiss da Língua Portuguesa.

Ciosos e cientes que somos de nossa identidade profissional, talvez não ocorra a nenhum historiador ou historiadora a necessidade de procurar sua própria definição no dicionário. Caso o façamos por qualquer motivo (para escrever uma resenha, quem sabe...), a busca não nos trará qualquer surpresa; ao contrário, como mostra a epígrafe, a obviedade da resposta só reforçará nossas convicções, além de provocar, provavelmente, a sensação de perda de tempo pelo trabalho um tanto inútil.

Um pouco mais de atenção, contudo, pode fazer com que esse exercício simples não se mostre tão vão ou desprezível. Organizada de modo nada casual, muito menos natural, a sequência de acepções da palavra revela, de saída, uma hierarquia entre os sujeitos e práticas dedicados ao registro verbal e/ou escrito daquilo que um dia ocorreu. Se "os historiadores sempre contaram histórias", como lembrava, já há quarenta anos, Lawrence Stone logo na primeira frase de seu famoso artigo "O retorno da narrativa" o modo de contá-las e, o que talvez seja o mais importante, o modo pelo qual se espera que elas sejam contadas mudaram bastante no correr dos séculos - particularmente nos últimos dois, desde que Leopold von Ranke anunciou que nossa tarefa deveria ser "apenas mostrar o que realmente aconteceu" e, mais importante, indicou como isso teria de ser feito para que a História, com inicial maiúscula, encontrasse seu lugar como Ciência.

Sabemos bem de tudo isso, é certo. Sabemos bem também que não foram poucos os debates e as polêmicas gerados por tal busca pela cientificidade, seja a partir de dentro, seja a partir de fora dos marcos da historiografia, não raro despertando "crises" que levaram a disciplina a se repensar e a se reformular. Não por acaso, a ela se vincula, direta ou indiretamente, uma das perguntas mais frequentes com as quais nos deparamos, senão a mais frequente: o que é História, afinal? Respostas eloquentes, algumas já clássicas, foram dadas a ela ao longo do século $X X$, e é desnecessário retomá-las aqui; interessa mesmo é destacar que tanto a pergunta quanto boa parte das respostas nem sempre parecem considerar em sua devida 
dimensão o agente da produção do conhecimento chamado "História" e tudo o que o envolve, de sua formação à sua trajetória, de suas origens à sua atuação. Dito de outra maneira, a figura do historiador muitas vezes fica em segundo plano nessas reflexões, como uma espécie de sujeito oculto da ciência que pratica.

Longe de pretender hipertrofiar a ação individual dos homens e mulheres dedicados ao estudo do passado, chamar a atenção para a sua importância significa lembrar que "a História" não se faz naturalmente, e sim pela prática. É graças a ela, a prática, que essa ciência se efetiva, se constrói, se desenvolve, se transforma. E, se é fácil aqui ouvir os ecos da operação historiográfica, tal como descrita por Michel de Certeau², vale apurar um pouco mais os sentidos para apreender e incorporar a eles uma lição ainda mais antiga, agora de Edward Hallet Carr: "antes de estudar a História, estude o historiador". ${ }^{3}$

Seguros conhecedores de ambos os ensinamentos e, sobretudo, de suas implicações, Julio Bentivoglio e Alexandre de Sá Avelar se empenharam em apresentar neste Afirmação da História como ciência no século XX um conjunto expressivo de nomes que marcam a historiografia contemporânea. Em dez breves, mas densos, ensaios, eles e outros onze colegas brasileiros analisam historiadores cuja obra e, em especial, prática tornaram-se referência incontornável para o que fazemos, buscando ressaltar seu lugar e seu impacto na escrita da História no decorrer da segunda metade do século XX - justamente o momento da afirmação da disciplina como ciência.

De saída, mostra-se crucial destacar que o livro dá continuidade a outro trabalho organizado por Julio Bentivoglio, este em parceria com Marcos Antônio Lopes, A constituição da História como ciência: de Ranke a Braudel, voltado, como o título indica, ao período anterior, inicial, desse percurso ${ }^{4}$; ao mesmo tempo, como informam os organizadores em seu prefácio, prepara o terreno para uma nova coletânea, que será dedicada a "autores vinculados à nova filosofia da História, ao narrativismo e ao revisionismo" pós-1970 (p. 10). Embora cada volume tenha plena autonomia em relação aos demais, a série, quando completa, se constituirá em um rico e instrutivo painel do que a historiografia produziu de mais significativo desde o Oitocentos, oferecendo assim um ganho imenso à bibliografia básica de nossa área disponível em português.

Neste livro, aparecem, pela ordem, Arlette Farge, Christopher Hill, Edward Palmer Thompson, Hans-Ulrich Gumbrecht, Hayden White, Jörn Rüsen, Michel de Certeau, Moses Finley, Reinhart Koselleck e Robert Mandrou. Um comentário óbvio, mas inevitável quando se trata de obras dessa natureza, é que o elenco que as constituem é sempre fruto de escolhas; no caso, escolhas conscientes e deliberadas, porém muito difíceis de fazer, levando-se em conta a pluralidade e a complexidade que a historiografia adquiriu no recorte abordado. Nesse sentido, é certo que a possibilidade de se questionar um ou outro nome presente, bem como de reivindicar um ou outro ausente, mostra-se permanentemente aberta. Não há como discordar dos organizadores, entretanto, quando dizem que "os autores selecionados permitem reconhecer tanto o processo de afirmação da História quanto sua resposta à crise que marcou os estudos históricos em meados do século XX e início do século XXI" (p. 9). Junto a esse aspecto, é por demais relevante notar também a variedade de culturas historiográficas que eles representam, algumas delas bem conhecidas e influentes no Brasil, outras nem tanto. Se, ao menos aparentemente, não há muito de novo a apresentar sobre

\footnotetext{
${ }^{2}$ Ver CERTEAU, Michel de. A operação historiográfica. In: $A$ escrita da História. 2. ed. Rio de Janeiro: Forense Universitária, 2006.

${ }^{3}$ CARR, Edward Hallet. Que é História? 6. ed. Rio de Janeiro: Paz e Terra, 1989, p. 41.

${ }^{4}$ Ver BENTIVOGLIO, Julio e LOPES, Marcos Antônio (orgs.). A constituição da História como ciência: de Ranke a Braudel. Petrópolis: Vozes, 2013.
} 
Thompson ou Certeau, por exemplo, decerto não se pode dizer o mesmo acerca de Gumbrecht, White ou mesmo Farge, inserida na tradição francesa que tanta penetração tem em nossa historiografia.

O fator geracional é outro elemento dessa seleção que merece ser posto em relevo por sua representatividade. Nascidos entre as décadas de 1910 e 1940, nenhum deles escapou, como indivíduo, à experiência dramática das guerras mundiais, particularmente a segunda, experiência essa que, em maior ou menor grau, marcou suas formas de ver o mundo e lidar com o presente, o passado e o futuro; nem, como historiador, aos questionamentos mais sistemáticos dirigidos ao modelo rankeano ao longo da primeira metade do século e às mudanças historiográficas deles decorridas - e, vale reiterar, é precisamente a colaboração decisiva de cada um ao aprofundamento de tais mudanças que nos permite vê-los como afirmadores da História como ciência.

Este dado, aliás, poderia ter sido explorado na elaboração da sequência dos capítulos, uma vez que a apresentação pela ordem alfabética do prenome do elenco dilui sua cronologia (quem vem antes, quem vem depois), apaga conexões efetivas (Mandrou e Farge, Hill e Thompson) e aproximações possíveis (White e Koselleck, por exemplo) e, ao se estender ao título do livro, ainda pode causar certo estranhamento, já que, em termos historiográficos, não faz sentido falar em "de Arlette Farge a Robert Mandrou" (inclusive porque, por coincidência, Mandrou foi orientador de Farge). Organizar o índice a partir do ano de nascimento dos autores, desse modo, poderia ser uma boa saída para deixar evidente já à partida que eles personificam ao menos duas gerações de historiadores do século XX.

Como também é comum acontecer em coletâneas, o conjunto dos ensaios não escapa a certo desequilíbrio interno. Há os mais densos, como os sobre Farge, escrito por Marlon Salomon, e White, escrito por Temístocles Cezar e Arthur Ávila; os mais completos, como aqueles que tratam de Certeau e Finley, o primeiro abordado pela dupla de organizadores do livro, o segundo por Gilvan Ventura da Silva; os que se aprofundam na análise do que o autor em questão tem de mais específico em seu pensamento sobre a História, caso daqueles sobre Thompson, discutido por Rodrigo Goularte, e Gumbrecht, por Thiago Vieira de Brito; os que buscam uma visão panorâmica sobre perspectivas historiográficas, como os sobre Hill, Rüsen e Koselleck, trabalhados por Josemar Machado de Oliveira, Cristiano Alencar Arrais e Rafael Saddi Teixeira e Julio Bentivoglio e Marcelo Durão Rodrigues da Cunha, respectivamente; por fim, há ainda um, em específico, que mostra-se muito original ao tratar de um historiador por meio de sua recepção crítica, apresentando as resenhas publicadas sobre alguns de seus principais trabalhos: aquele sobre Robert Mandrou, escrito por Wilton Silva.

O desequilíbrio, portanto, não significa aqui algo ruim ou negativo: de um lado, ele expressa o quão difícil é produzir textos dessa natureza; de outro, as muitas entradas possíveis para se compreender a complexidade e o refinamento não somente dos historiadores selecionados, mas, por extensão, da própria historiografia contemporânea. Em sua argumentação específica, cada capítulo cumpre muito bem o papel de oferecer uma introdução sólida e segura à vida e à obra dos autores selecionados, o que não é pouco, evidentemente. Mas, os textos vão muito além desse caráter de divulgação, o qual talvez interessasse mais, por pragmatismo, aos estudantes de História e àqueles que, por necessidade ou curiosidade, quisessem 
saber deste ou daquele nome. Ao sistematizarem a contribuição que os dez citados deram à afirmação da História como ciência, seus intérpretes produzem eles próprios interpretações historiográficas significativas, todas marcadas por observações sagazes que instigam o/a leitor/a a reflexões mais amplas, ultrapassando os limites do livro.

Sem querer estragar o prazer da leitura e das descobertas que ela proporcionará, têm grande brilho, por exemplo, a identificação de Arlette Farge ao "seu" arquivo; a menção ao "não conformismo" que marcou as opções políticas e acadêmicas de Christopher Hill; o destaque para a ênfase que E. P. Thompson dava ao "preparo árduo" exigido pela historiografia; a atenção à chave da "experiência" no trabalho de Hans-Ulrich Gumbrecht; a lembrança sempre necessária de que Hayden White, recentemente falecido, foi, sim, historiador; a interpretação do vínculo entre Teoria da História e Didática da História proposto por Jörn Rüsen; a caracterização de Michel de Certeau como um intelectual dotado de "força interdisciplinar" e "poder iconoclasta"; a busca pelas múltiplas conexões de M. I. Finley em sua atuação como historiador da Antiguidade; a apresentação da História dos Conceitos de Reinhart Koselleck como uma teoria da História; e, finalmente, a elaboração do perfil de Robert Mandrou sob o pano de fundo dos cânones historiográficos e das disputas nada tranquilas que muitas vezes os envolvem.

Como decerto já se notou, apenas uma historiadora figura nessa lista de autores. Sem prejuízo do que foi dito mais acima acerca da natureza necessariamente seletiva do livro, tal desproporção reflete a presença também desproporcional de homens e mulheres no cenário da nossa disciplina, situação que começa a mudar apenas nas últimas décadas do século passado. Trata-se, assim, de uma lacuna eloquente, que diz mais sobre os caminhos (e descaminhos) da historiografia moderna que sobre as escolhas dos organizadores - e que, por esse mesmo motivo, merece atenção quando tratamos, como também foi apontado no início, dos agentes e práticas que fizeram e fazem a História como ciência.

Para encerrar, duas citações podem ilustrar à perfeição o imenso valor desta coletânea. Uma é dela própria, por coincidência extraída do ensaio de Marlon Salomon sobre Arlette Farge: "é comum buscar caracterizar o trabalho historiográfico de um autor por meio da identificação da escola ou da tendência teórica a qual ele pertence ou a qual se vincula sua formação. É o modo mais simples e confortável de se atribuir identidade teórica a alguém. Sabemos, no entanto, que a realidade é mais complexa do que os rótulos escolares" (p. 11). A outra traz de volta E. H. Carr, que já em 1961 recomendava, na mesma linha da lição anteriormente mencionada: "quando você lê um trabalho de História, procure saber o que se passa na cabeça do historiador. Se não conseguir, o defeito é seu ou dele". ${ }^{5}$ Graças ao empenho de Julio Bentivoglio, Alexandre de Sá Avelar e dos autores de cada capítulo, Afirmação da História como ciência no século XX é um grande antídoto a rótulos fáceis e incompreensões teóricas. 